\title{
KEY PERFORMANCE INDICATORS OF 'GOOD PRACTICES' OF ENERGY EFFICIENCY IN INDUSTRY: APPLICATION TO REAL CASES IN ITALY AND IN THE EUROPEAN UNION
}

\author{
REALINI ANNA, MAGGIORE SIMONE, ZAGANO CLAUDIO \& FRANCHIONI GIORGIO \\ RSE - Ricerca sul Sistema Energetico S.p.A. \\ Via Rubattino, Milano (ITALY).
}

\begin{abstract}
With the publication of the Energy Efficiency Directive (EED) in 2012, energy savings in the Industry processes have gained more and more importance in the European Union (EU). Industry (with building and transport) is one of the three main sectors where Energy consumption and efficiency play a fundamental role, to accomplish the EU energy objectives. Many countries in EU have already adopted schemes and mechanisms to implement the Directive: however deep differences of approaches still remain among the Member States (MSs), especially with respect to the identification of the real benefits of measures and to the assessment of their efficiency and sustainability. As a consequence, a huge amount of the efficiency potential still remains untapped. This paper proposes some criteria for the evaluation of the applied Energy Efficiency measures, leading to the identification of Good Practices of Energy Efficiency. These criteria are taken from the 'real world' of industry, and are susceptible to be replicated in other contexts (e.g. different sectors or other countries). The proposed criteria have been developed in the EU H2020 project EUMERCI (nr 693845) and through a national research (part of the 'Ricerca di Sistema' national funding system) both coordinated by RSE. The starting point is the harmonization of data sets related to projects developed in different EU countries within local efficiency implementation schemes. The second step is the definition of Key Performance Indicators (KPIs) reflecting the impact of measures against Energy, Environment and Economic aspects. The last step is the extraction of efficiency 'Good Practices' ranked according to the identified KPIs and other factors, including social elements. The real added value of this approach is that it is full based on tangibly implemented projects, in opposition to similar attempts, essentially theoretical. Ultimately, it offers a key of assessment of the effectiveness of efficiency measures implementing local and EU policies. Keywords: energy efficiency, good practices, industry, key performance indicators
\end{abstract}

\section{INTRODUCTION}

Energy efficiency has gained more and more relevance in the European Union after the publication of the Energy Efficiency Directive 2012/27/EU (EED). Through this Directive, the European Commission (EC) sets clear goals of energy consumption reduction that each Member State (MS) shall accomplish in the next years. The first set of objectives is aimed at a reduction of $20 \%$ in final energy consumption by 2020 . The main contributions to achieve this goal come from three different sectors: Buildings, Transport and Industry. According to EUROSTAT ([11]), in 2014 industry was responsible for $25.9 \%$ of the Final Energy Consumption of the European Union. The need of improving energy efficiency in the industrial sector is clearly defined in the Strategic Energy Technology Plan (SET Plan), whose action 6: 'Energy Efficiency in Industry', sets targets for 2020 and a vision for 2050.

In order to incentivise the adoption of Energy Efficiency measures, most EU MSs have already put in place policies such as Voluntary Agreements, Energy Efficiency Obligation Schemes (EEOS), Financial Supports and Fiscal Measures. After an analysis and comparison of the different policies in the MSs, the EU-MERCI project (acronym for 'EU coordinated methods and procedures based on real cases for the effective implementation of policies and 
measures supporting energy efficiency in the industry'), funded by the European Commission under the Horizon 2020 programme (Grant Agreement nr. 693845), has developed a database of a huge number of energy efficiency measures and projects really put in place in some MSs (Austria, Italy, Poland and United Kingdom, at the moment); the goal is to select the most effective combinations of methods and technologies to support energy efficiency and to recommend their incentivisation. The so-identified 'Good Practices' (GPs) will be fully described and made available in an open-access online portal (the EU-MERCI portal), where the whole database of measures and projects will also be accessible. Moreover, the GPs will be validated by industrial stakeholders, in order to confirm their in field applicability and sustainability. The added value of this work is that the identified 'Good Practices' are taken from the 'real world', rather than being the result of a theoretical study, and are based on the analysis of actual energy audits and balances presented by the implementing actors (manufacturing companies). This approach provides clear indications on the technical feasibility and economic affordability of the projects for the concerned stakeholders. The GPs will also be analysed from a policy point of view, in order to understand whether the schemes used to support the efficiency were actually the most effective and, if the case, to recommend improvements of the schemes themselves and of their incentivisation policies. The first part of this paper presents the process of harmonization of the available data sets related to measures and projects implemented in different EU countries, in order to build the EU-MERCI database and allow a benchmarking of the practices; the second part explains the methodology used to identify the 'Good Practices', focusing on the developed Key Performance Indicators (KPIs). Finally, some examples of 'Good Practices' in the Pulp and Paper sector are presented, in order to show concrete applications of the methodology.

\section{BUILDING THE EU-MERCI DATABASE}

As mentioned above, after an analysis and comparison of energy efficiency policies and schemes adopted in the different MSs, data sets of energy efficiency measures and projects implemented in four selected countries (Austria, Italy, Poland, UK) were collected for different industrial sectors. The four MSs are respectively represented in EU-MERCI by AEA, RSE, KAPE and Carbon Trust, in overall identified as the 'Enablers', as those institutions have access, under different titles in the respective countries, to the information related to the implemented energy efficiency projects, within the national incentivising mechanisms. The main difficulty of this step was the harmonization of the data sets, considering the very wide variety of quality and level of detail of the data made available by the different sources.

\subsection{Selection of the sectors}

The analysis has been focused on the manufacturing field (categorized under the ' $\mathrm{C}$ ' code according to the NACE classification), which is also the mostly represented in the available data sets. Within this field, industry sectors were selected according to the following energy consumption and economic impact indicators: Final Energy Consumption, Energy Cost over Value Added, Number of Employees, Gross Value Added, Energy Efficiency Economic potential (Pay-back time lower than 5 years) and Energy Efficiency technical potential (Mtoe). The ranking led to the selection of the below listed sectors :

- Manufacture of food products - Manufacture of beverages - NACE C10-C11;

- Manufacture of pulp and paper products - NACE C17; 
- Manufacture of coke and refined petroleum products - NACE C19;

- Manufacture of chemicals and chemical products - NACE C20;

- Manufacture of other non-metallic mineral products (divided into glass, ceramic and cement) - NACE C23;

- Manufacture of basic metals (divided into iron and steel and other metals) - NACE C24;

- Machinery - NACE C25-28.

The number of available data for each country in each sector is reported in Table 1 (the total number of available records is 2,937). Food and beverage sector is the most represented, followed by machinery. From a country perspective, Poland has the lowest amount of available data, due to the fact that their White Certificates mechanism has been implemented recently only.

\subsection{Useful data and harmonization process}

The second step of the database construction has been the identification of the data fields mostly effective to describe the measures and projects put in place and to allow an in-depth analysis aimed at the definition and selection of the 'Good Practices'. After some considerations about the needed level of detail and the availability of data from the different national data sets, the following fields have been selected as the most relevant for a full picture of the actual status of the implemented measures and projects:

- Sector, with at least the first two numeric digits of the NACE Code (up to 4 digits where available);

- Location (country);

- Company Size (Small, up to 50 employees; Medium, from 51 to 250 employees; Large, more than 250 employees);

- Full textual description of the adopted measure;

- Energy carriers involved in the measure (from 1 to 5);

- Baseline of the consumptions (where available, specific to the process or plant);

- Achieved savings;

- Overall cost of the implemented measure or project;

- Cumulative amount of incentives granted to the measure or project.

Table 1: Available records by sector and by country.

\begin{tabular}{llllll}
\hline & \multicolumn{2}{l}{ Data available per country } & & \\
\cline { 2 - 6 } NACE sector & Austria & Italy & Poland & UK & Total \\
\hline C10-11 & 305 & 102 & 112 & 316 & $\mathbf{8 3 5}$ \\
C17 & 34 & 135 & 1 & 116 & $\mathbf{2 8 6}$ \\
C19 & 0 & 32 & 4 & 8 & $\mathbf{4 4}$ \\
C20 & 30 & 123 & 25 & 185 & $\mathbf{3 6 3}$ \\
C23 & 8 & 257 & 24 & 87 & $\mathbf{3 7 6}$ \\
C24 & 14 & 146 & 31 & 107 & $\mathbf{2 9 8}$ \\
C25-28 & 296 & 59 & 4 & 376 & $\mathbf{7 3 5}$ \\
Total & $\mathbf{6 8 7}$ & $\mathbf{8 5 4}$ & $\mathbf{2 0 1}$ & $\mathbf{1 1 9 5}$ & $\mathbf{2 9 3 7}$ \\
\hline
\end{tabular}


Moreover, a 3-levels taxonomy has been built in order to classify the measures and projects into standard categories, according to the part of the plant portion where they have been applied to (1st level taxonomy: e.g. 'Process technology' or 'Service technology' or 'Alternative Energy production'), the phase of the process (2nd level taxonomy) and the specific involved technology (3rd level taxonomy), both in generic terms ('Generic taxonomy', e.g. 'Heat recovery') and in sector-specific terms ('Specific taxonomy', e.g. 'Paper making machine'). For simple interventions, called 'Single measures', there shall be one classification in the generic taxonomy (three levels of detail) and one in the specific taxonomy (three levels of detail). For more complex interventions, called 'Combined measures', it is possible to specify two generic and two specific taxonomy classifications (each composed of three levels of details).

\section{3 'GOOD PRACTICE' DEFINITION AND KEY PERFORMANCE INDICATORS}

The core of the EU-MERCI project is the definition of 'Good Practice'. It is well known what a 'Best Available Technique' is, but the first question to deal with is whether such a technique is technically feasible and economically affordable in the reality: the concept of 'Good Practice' tries to address this important issue.

\subsection{Best Available Technique and 'Good Practice' definition}

While there are several documents describing the 'Best Available Techniques' in different sectors, only few of them consider the real applicability of the proposed solution, often stopping at their theoretical potential. A great advantage of EU-MERCI project is the availability of about 3,000 data describing Energy Efficiency measures and projects taken from the real world. This means that all the records reported in the database have been put in place in one MS and have been deemed eligible to be incentivised in the MS by experts in the sector. This is fully reflected in the definition of 'Good Practice' according to EU-MERCI, which is 'a technique or a methodology that, through experience and research, has been proven to reliably lead to a desired result with the minimum use of resources.' This means that each proposed 'Good Practice' satisfies the following criteria at the same time:

- It is efficient;

- It is technically feasible;

- It is economically affordable.

Additional criteria of selection of a EU-MERCI GP in a sector are its replication potential in different MSs and its exportability to other sectors.

\subsection{Key Performance Indicators}

In order to identify which projects referred to in the 3,000 records could be eligible as 'Good Practices', three complementary approaches have been chosen:

- Statistical analysis of the dataset, e.g. the number of occurrences for each type of intervention in one sector or in different sectors;

- Engineering expertise, in order to assess the real added value of the practice (i.e. its innovation character and the technical appeal); 
- Use of key performance indicators (KPIs), so as to objectively quantify the benefits of the practice.

Statistical analysis is strictly dependent on the available data, as well as engineering expertise. KPIs definition, on the contrary, is independent from the database, with the advantage that it might be replicated in other projects and evaluations. The definition of KPIs, however, takes into account also the quality of available data, in order to be able to calculate them on the EU-MERCI database.

\subsubsection{Technical KPIs}

The first set of KPIs considers the energy performances of the implemented projects.

1. Primary Energy Savings

The Primary Energy Savings (PES) allow to compare, with a unique indicator, the Final Energy Savings (FES) generated by measures involving different carriers, in particular thermal and electrical energy savings.

The equation used for PES is reported below, where $\mathrm{k}$ is the energy carrier.

$$
\operatorname{PES}\left[\frac{\text { toe }}{\mathrm{y}}\right]=\sum_{k=1}^{n} \mathrm{FES}_{\mathrm{k}} \cdot \text { Conversion } \text { factor }_{k} \text {. }
$$

The Conversion factor takes into account the efficiency of the generation and transmission chain (from primary to final energy) for the considered carrier. In order to align and compare all the data from different countries, the choice has been to use average European conversion factors.

2. Energy Consumption Improvement (Efficiency)

The Energy Consumption Improvement (ECI) indicator is used to assess the improvement of energy performances achieved with the efficiency measure with respect to the condition before implementation. The equation is reported below. Baseline, as reported in the database, shall be converted into primary energy as well, before ECI calculation.

$$
\operatorname{ECI}[\%]=\frac{\operatorname{PES}\left[\frac{\text { toe }}{\mathrm{y}}\right]}{\text { Primary Baseline }\left[\frac{\text { toe }}{\mathrm{y}}\right]} \cdot 100 \text {. }
$$

3. Energy Intensity

The Energy Intensity (EI) indicator is usually defined as the energy input used to obtain one unit of product in output. In the database, only the overall production value of the specified sector is available. Therefore, Energy Intensity has been defined as reported in eqn (3). Production value data have been taken from [1].

$$
\mathrm{EI}\left[\frac{\mathrm{toe}}{\mathrm{k} €}\right]=\frac{\operatorname{PES}\left[\frac{\text { toe }}{\mathrm{y}}\right]}{\text { Produced value }\left[\frac{\mathrm{k} €}{\mathrm{y}}\right]} .
$$




\subsubsection{Economic KPIs}

The second set of KPIs considers the economic performances of the implemented projects.

1. Simple Pay-back Time

The Simple Pay-back Time (PBT) indicator is calculated as the period of time after which the investment is completely paid back. Since the EU-MERCI database considers investments in Energy Efficiency performed in different countries and years under different implementation support schemes, it has been decided not to take into account the discount rate, and to consider each project as not incentivised. This last choice has been taken in order to understand which of the implemented measures could be replicated also in absence of support schemes and which ones would require higher incentives from policy actions.

$$
\mathrm{PBT}[\text { years }]=\frac{\text { Investment }}{\sum_{k=1}^{n} \mathrm{FES}_{\mathrm{k}} \cdot \text { Energy carrier cost }_{k}} .
$$

Energy carrier cost is different, for some carriers, in the considered countries. It has been chosen to use an average EU-28 cost, in order to be able to align and compare the different measures ([11]).

2. Cumulative Cash Flow

Complementary to Simple Pay-back Time, the Cumulative Cash Flow (CCF) indicator is a measure of the incomes generated by the energy savings achieved with the adoption of the energy efficiency measure. Also in this case, it has been chosen not to take into account the discount rate, and to consider each project as not incentivised.

$\mathrm{CCF}[$ years $]=-$ Investment cost $+\left(\sum_{k=1}^{n} \mathrm{FES}_{\mathrm{k}} \cdot\right.$ Energy carrier cost $_{k} \cdot$ Technical life $)$.

3. Share of Project Cost Subsidized

The Share of Project Cost Subsidized (SPCS) indicator is a measure to verify how much of the project has received incentives from policy actions. The index may support also the analysis of the quality of each policy, especially for those policies that set incentives based on the achieved savings and not proportional to the investment cost (e.g. Italian White Certificates mechanism).

$$
\operatorname{SPCS}[\%]=\frac{\text { Received subsidies }[\mathrm{k} €]}{\text { Investment } \operatorname{cost}[\mathrm{k} €]} \cdot 100 .
$$

\subsubsection{Advanced KPIs}

The KPIs of the last set are called 'advanced' because they either take into consideration both technical and economic performances of the measure or their assessment is based on other factors, like the impact on the environment of the implemented projects.

1. Renewable Energy Use

The Renewable Energy Use (REU) indicator considers the percentage of savings associated to the use of renewable energy sources. It is defined in equation (7), where Renewable Energy is measured in primary energy, as the Primary Energy Savings in the denominator are. 


$$
\operatorname{REU}[\%]=\frac{\sum_{k=1}^{n} \mid \mathrm{FES}_{\mathrm{k}} \cdot \text { Conversion } \text { factor }_{k} \cdot \text { RES factor }{ }_{k} \mid}{\sum_{k=1}^{n} \mid \mathrm{FES}_{\mathrm{k}} \cdot \text { Conversion factor } r_{k} \mid} \cdot 100
$$

This KPI is specifically designed for those cases in which PES might be equal or less than 0: the use of absolute values allows to consider also the 'negative savings', typically those related to the increase in use of biomass, wind or other renewable sources.

RES factor is considered equal to 0 for fossil fuels; equal to 1 for biomass, wind, solar and other renewable energy sources; for industrial wastes, end-of-life tyres and other mixed sources, it is calculated using standard values from literature or, if available, directly from the specific measure description (thus the values range from 0 to 1 ).

2. Cost of Energy Savings

Cost of Energy Savings (CES) represents the capital invested in the implemented efficiency project per ton of saved oil equivalent. The equation to calculate it is equation (8).

$$
\mathrm{CES}\left[\frac{\mathrm{k} €}{\text { toe } / \mathrm{y}}\right]=\frac{\text { Investment }[k €]}{\sum_{k=1}^{n} \operatorname{PES}_{\mathrm{k}}\left[\frac{\text { toe }}{y}\right]}
$$

3. Cost of Carbon Savings

Cost of Carbon Savings (CCS) represents the capital invested in the implemented efficiency project per ton of saved $\mathrm{CO}_{2}$ emissions.

$$
\mathrm{CCS}\left[\frac{\mathrm{k} €}{\text { ton } \mathrm{O}_{2} / y}\right]=\frac{\text { Investment }}{\sum_{k=1}^{n} \mathrm{FES}_{\mathrm{k}} \cdot \mathrm{CO}_{2} \text { emission } \text { factor }_{k}}
$$

The $\mathrm{CO}_{2}$ emission factor depends on the energy carrier. It has been taken equal to zero for all the renewable energy sources, including biomass (considered at zero carbon balance) and nuclear. The use of direct $\mathrm{CO}_{2}$ emissions criterion was preferred to the Life-Cycle Assessment (LCA) approach, due to the difficulty in computing LCA emission for all carriers in different countries and sectors.

\section{3 'Good Practices' selection: three-ways approach}

In parallel to the KPIs calculation, two other complementary approaches have been applied to the database with the aim of selecting the 'Good Practices', as above explained.

\subsubsection{Engineering Expertise}

Engineering expertise is the most time-consuming approach. It implies that the database investigators have a deep knowledge of industrial processes and a solid technical background of energy efficiency issues and measures. The approach requires the reading in depth of all the detailed descriptions of the measures as available in the database and the investigation and detection of further information in the full audit reports of the implemented projects when a record sounds promising. Basing on the Engineering expertise, each Enabler has completed a list of preliminary technical 'Good Practices' from its own national data-set, to be then compared with the results coming from the KPI analysis. 


\subsubsection{Statistical analysis}

A statistical sector analysis of the database has been performed in order to evaluate how often a defined technology or type of intervention has been performed, in which sectors, in which years and in which country. The statistical analysis includes a cost analysis of the different measures, with respect to the achieved savings. It gives an idea on efficiency trends of Industry and, together with KPIs, should help to understand the reasons behind them.

\subsubsection{Records ranking according to KPIs}

After KPIs are calculated on the whole database, a ranking of the records is performed for each sector, using the following criteria:

- Average, median, quartiles (every 10\%) are calculated for all KPIs for each sector.

- A measure is rated based on its performance with respect to all the other records in the sector. If the measure is amongst the $10 \%$ best performers (better than $90 \%$ of all records) it will get 10 Points. If it performs better than $80 \%$ of the records, it will get 9 points, and so on. This procedure is repeated for all KPIs. The Sum of the individual KPI ratings yields the total rating of the measure.

- The sum takes into account a weight associated to each KPI, that can be modified according to the relevance given to the different aspects (e.g. technical, economic or focused on Renewable Energy Sources).

- The best performing measures according to the above criteria are firstly classified as potential 'Good Practices'. The threshold is defined by each enablers upon the completion of the KPI rating of the sector specific datasets.

\subsubsection{Combination of the three methods}

Once both potential 'Good Practices' have been identified, through engineering expertise and records ranking according to KPIs, and a statistical analysis on the recurrence of the different types of interventions has been performed, the three approaches are combined together in order to obtain a final list of 'Good Practices' for each analysed sector. An example is shown below in the Table 2 .

The recurrence in the datasets is considered as a further KPI, in order to build a ranking of the KPIs whose cumulative rating is 100 points. However, recurrence will be weighted less than the other KPIs. This will be combined with Engineering Expertise evaluation in order to build a final list of Good Practices to be validated by external stakeholders.

Table 2: Three-ways approach to 'Good Practices' definition - example.

\begin{tabular}{llll}
\hline record id & Engineering Expertise GP & Recurrence in the dataset & KPI rating \\
\hline 0001 & Yes & $20 / 245$ & $23 / 90$ \\
0002 & No & $40 / 245$ & $54 / 90$ \\
0003 & Yes & $5 / 245$ & $71 / 90$ \\
$\ldots$ & $\ldots$ & $\ldots$ & $\ldots$ \\
\hline
\end{tabular}




\section{PRELIMINARY RESULTS: CASE STUDIES FROM THE EU-MERCI \\ DATABASE}

The final identification of 'Good Practices' is still ongoing at the moment of writing this paper. However, for some sectors, preliminary results are available. Some case studies from the Pulp and Paper sector are reported in this paragraph.

For the Pulp and Paper sector, different 'Good Practices' can be identified. The three cases presented here are just examples, in order to show how the methodology works and, in particular, how KPIs and Engineering expertise can be combined.

\subsection{Roll coating machines revamping through burners optimization}

This efficiency improvement is a combined measure applied to the paper-making process, more specifically, to the final section of the paper-making machine. The intervention consists in the replacement of one of the four roll coating machines of the plant, in order to reduce natural gas and electricity consumptions. This goal has been accomplished by installing a new hot air system, with burners distributed in the drying tunnel in order to reduce heat loss and have a more homogeneous temperature distribution. Then a revamping of the air recirculation system has been put in place. The final result is a reduction of the load on the fans, which are also equipped with inverters (Variable Speed Drives), so as to increase their efficiency.

The main parameters characterizing the measure are:

- Baseline (process specific): 1,938 toe/y

- Primary Energy Savings (PES): 1,053 toe/y

- Energy Consumption Improvement (ECI): $54 \%$

- Cost of Carbon Savings (CCS): 2,730 €/tonCO 2

- Payback Time (PBT): 15.1 years

- Share of Project Cost Subsidized (SPCS): $6 \%$

This measure has very high PES and also a high ECI. This means that it allows to significantly decrease the energy consumption of the process. However, its PBT is also quite high, due to a high investment cost (around 7,000 k€). From a technical point of view, the adoption of a new geometry for the burners and the air circulation system, together with the installation of inverters on the fan, is a complex design, that requests adequate engineering support. This measure is recurring only once in the database. With higher incentives (SPCS), that allow to reduce the PBT, the replication in other plants could be boosted.

\subsection{Mechanical pulping grinding plate teeth}

This efficiency improvement is a single measure applied to the mechanical pulping process, preliminary to (preparatory of) paper-making. The intervention consists in the realization of a new grinding plate with teethed surface. This surface has improved cutting qualities and needs lower electricity to grind the same amount of wood. The reduction of consumption is linked to the reduction in re-grinding phenomenon, which is the permanence of the pulp on the surface of the grinder, which increases electrical consumption. The new plate has a geometry that allows the pulp to be distributed on the sides of the grinder, so reducing re-grinding effect. The intervention recurs once in the paper sector database. 
The main parameters characterizing the measure are:

- Baseline (process specific): 5,883 toe/y

- Primary Energy Savings: 1,150 toe/y

- Energy Consumption Improvement (ECI): $20 \%$

- Cost of Carbon Savings (CCS): $110 € /$ tonCO 2

- Payback Time (PBT): 0.5 years

- Share of Project Cost Subsidized (SPCS): Not available (N/A)

This measure is an example of a technically simple project, allowing to obtain very high PES and ECI, with a very low investment cost (around $300 \mathrm{k} €$ ), that can be paid back in less than one year. This case is the typical example of an efficient technology with such a level of maturity that might make not-decisive the incentives support.

\subsection{Dual cleaner on paper-making machine drying section}

This efficiency improvement is a single measure applied to the drying section of the paper-making machine. It consists in the installation of a dual cleaner, which allows to reduce natural gas consumption and to avoid contamination of the paper sheet by impurities in the transport system, while improving the cleanliness of the paper transport frame. The removal of dirt improves the heat exchange on the paper surface, so reducing the load of the dryers. The intervention recurs three times in the paper sector database.

The average parameters characterizing the measure are:

- Baseline (process specific): 10,311 toe/y

- Primary Energy Savings: 661 toe/y

- Energy Consumption Improvement (ECI): 6.5\%

- Cost of Carbon Savings (CCS): $799 € /$ tonCO $_{2}$

- Payback Time (PBT): 5 years

- Share of Project Cost Subsidized (SPCS): $27 \%$

This is a case where the PBT is aligned to an average investment in industry. PES is quite high, although the ECI is lower than in the previous case, due to the high baseline of the drying phase (high volumes of steam and natural gas are required). This measure, however, is simple to implement, with low installation times, so not influencing the production rate in the long run. This measure can be considered at 'average' maturity, still requiring incentives to make it more attractive, but presumably applicable also with lower or no incentives.

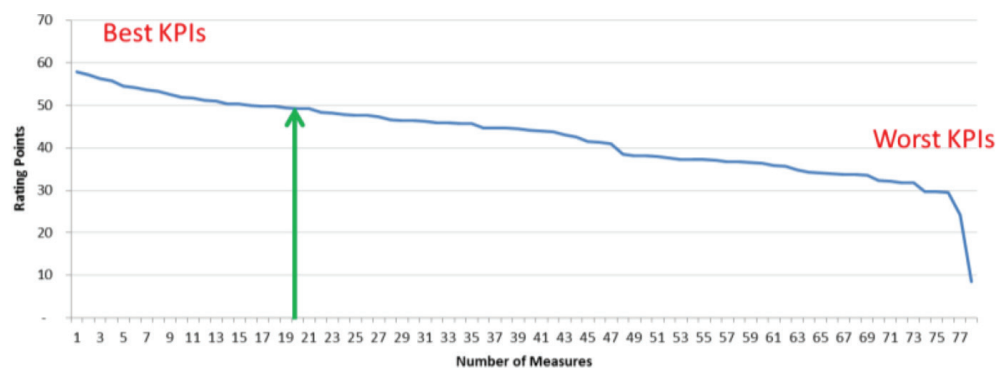

Figure 1: Ranking of 'Good Practice' 4.1 in the Combined cases KPIs analysis. 


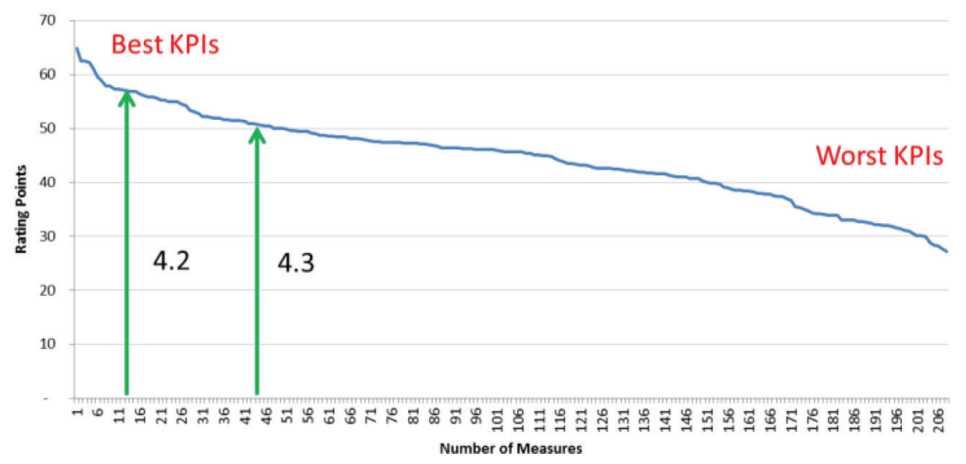

Figure 2: Ranking of 'Good Practices' 4.2 and 4.3 4.1 in the single cases KPIs analysis.

\subsection{Final considerations}

The 'Good Practice' presented in 4.1 has a score of 49 points (the maximum score in the sector is 58) in the KPIs ranking for Combined cases. The high technical quality has been already discussed previously, but also from a statistical and numerical approach it can be considered one of the best measures to apply.

The 'Good Practices' presented in 4.2 and 4.3 have, respectively, a score of 57 and 51 in the ranking for Single cases, with a maximum score for the sector equal to 65 . The technical aspects for these cases have been already discussed above and KPIs full analysis confirms that they are among the best measures for the sector.

The three-ways approach is rather complex to apply and requires an in-depth analysis of each measure that can be very time-consuming. However, it is deemed very reliable to achieve valuable and validated results, assuring both technical originality and high performances of the selected EU-MERCI 'Good Practices'.

\section{CONCLUSIONS AND FUTURE DEVELOPMENTS}

The EU-MERCI project has just passed its first half of duration. The preliminary results are promising, but a lot of work has still to be performed to achieve all the original targets. The identified KPIs are a strong support for the choice of GPs and, being defined independently from the database, can be applied also in similar works about Energy Efficiency in Industry and other energy-intensive sectors. Moreover, the methodology, once fully developed, will be made publicly available for anyone who wants to perform a similar work in her/his own country or in other Manufacturing sectors.

With regards to the project, the next steps will be the completion of the final list of 'Good Practices' for all the selected sectors and the preparation of the open portal to make the results and the methodology accessible to the interested users (Single companies, Sectoral Associations, ESCOs, Energy Managers, Policy Makers, etc...). In the meantime, during summer 2017, the validation of 'Good Practices' by stakeholders will take place, allowing Enablers to consolidate the GPs definition and assessment. A further action of EU-MERCI will be the transfer of the achieved results to the concerned stakeholders, through aimed Capacity Building initiatives implemented in the countries represented in the project Consortium. Finally, the last step of the EU-MERCI project will concern the assessment of the suitability of the actual EU efficiency framework (policies, Directives and schemes) to support the dissemination and exploitation of the identified GPs, e.g. through aimed incentivization initiatives: recommendations for improvements will be possibly provided to policy makers. 


\section{ACKNOWLEDGEMENTS}

RSE project team (the Authors) would like to thank the colleagues from Österreichische Energieagentur (AEA), Krajowa Agencja Poszanowania Energii S.A. (KAPE), Carbon Trust, Federazione Italiana per l'uso Razionale dell'Energia (FIRE) and Center For Renewable Energy Sources (CRES) for the fruitful cooperation in building the database, refining the KPIs definition and finalizing the 'Good Practice' identification methodology. Moreover, we are very grateful to our colleagues Elena Gobbi, Corine Nsangwe Businge, Francesca Bazzocchi and Marco Borgarello for providing useful data about the Italian Industry and constant support to the project.

\section{REFERENCES}

[1] Chan, Y. \& Kantamaneni, R., Study on energy efficiency and energy saving potential in industry from possible policy mechanisms, ICF Consulting Limited: London, 2015.

[2] IEA (International Energy Agency), Capturing the multiple benefits of energy efficiency. OECD/IEA: Paris, 2014.

[3] IEA (International Energy Agency), Energy efficiency indicators - highlights. OECD/ IEA: Paris, 2016.

[4] Kramer, K.J., Masanet, E., Xu, T. \& Worrell, E., Energy efficiency improvement and cost saving opportunities for the pulp and paper industry, Ernest Orlando Lawrence Berkeley National Laboratory: Berkeley, CA, 2009.

[5] ODYSSEE - MURE, Energy efficiency trends and policies in industry - an analysis Based on the ODYSSEE and MURE Databases, ADEME: Angers, France, 2015.

[6] Rota, L. \& Zagano, C., Misure di Efficienza Energetica nel settore industriale - RDS 15000306, RSE: Milano, 2015

[7] Suhr, M., Klein, G., Kourti, I., Rodrigo Gonzalo, M., Giner Santonja, G., Roudier, S. \& Delgado Sancho, L., Best available techniques reference document for the production of pulp, paper and board, Publications Office of the European Union: Luxembourg, 2015.

[8] DIRECTIVE 2012/27/EU OF THE EUROPEAN PARLIAMENT AND OF THE COUNCIL of 25 October 2012 on energy efficiency, amending Directives 2009/125/ EC and 2010/30/EU and repealing Directives 2004/8/EC and 2006/32/EC, Official Journal of the European Union, available at: http://eur-lex.europa.eu/legal-content/EN/ TXT/PDF/?uri=CELEX:32012L0027\&from=EN. (Accessed 30 September 2016).

[9] Guidance note on Directive 2012/27/EU on energy efficiency, amending Directives 2009/125/EC and 2010/30/EC, and repealing Directives 2004/8/EC and 2006/32/EC Article 8: Energy audits and energy management systems - (SWD/2013/0447 final), EU Commission, available at: http://eur-lex.europa.eu/legal-content/EN/TXT/HTML/?uri= CELEX:52013SC0447\&from=EN. (Accessed 30 September 2016).

[10] Industrial Efficiency Technology Database - Pulp and paper, available at: http://ietd. iipnetwork.org/content/pulp-and-paper. (Accessed 27 January 2017).

[11] Statistics Explained - Consumption of Energy; Eurostat, available at: http://ec.europa. eu/eurostat/statistics-explained/index.php/Consumption_of_energy. (Accessed 13 October 2016). 